\title{
Retraction note: Down-regulation of microRNA-26a and up-regulation of microRNA-27a contributes to aggressive progression of human osteosarcoma
}

Afshin Taheriazam¹, Reza Bahador ${ }^{2}$, Seyyed Hasan Karbasy ${ }^{3}$, Seyed Mir Mansoor Moazen Jamshidi ${ }^{4}$ Ali Torkaman ${ }^{5}$, Emad Yahaghi $^{6}$ and Mohammadreza Shakeri ${ }^{2 *}$

\section{Retraction}

The Editor-in-Chief and Publisher have retracted this article [1] because the scientific integrity of the content cannot be guaranteed. An investigation by the Publisher found it to be one of a group of articles we have identified as showing evidence suggestive of attempts to subvert the peer review and publication system to inappropriately obtain or allocate authorship. This article showed evidence of plagiarism (most notably from the articles cited [2-4]) and authorship manipulation.
3. Xue Z, Zhao J, Niu L, An G, Guo Y, Ni L. Up-regulation of MiR-300 promotes proliferation and invasion of osteosarcoma by targeting BRD7. PLOS ONE. 2015;10(5):e0127682.

4. Dadpay M, Zarea M, Rabati RG, Rezakhaniha B, Barari B, Ehnod V, Ziari K. Upregulation of miR-21 and downregulation of miR-494 may serve as emerging molecular biomarkers for prediagnostic samples of subjects who developed nasopharyngeal carcinoma associates with lymph node metastasis and poor prognosis. Tumour Biol. 2015. doi:10.1007/s13277-015-3905-1.

\begin{abstract}
Author details
${ }^{1}$ Department of Orthopedics Surgery, Tehran Medical Sciences Branch, Islamic Azad University, Tehran, Iran. ${ }^{2}$ Department of Orthopaedic and Trauma Surgery, Birjand University of Medical Sciences, Birjand, Iran. ${ }^{3}$ Department of Anesthesiology, Birjand University of Medical Sciences, Birjand, Iran. ${ }^{4}$ Department of Orthopedics, Zanjan University of Medical Sciences, Zanjan, Iran. ${ }^{5}$ Department of Orthopedics, Firoozgar Hospital, Iran University of Medical Sciences, Tehran, Iran. ${ }^{6}$ Department of Molecular Biology, Baqiyatallah University of Medical Sciences, Tehran, Iran.
\end{abstract}

Received: 17 October 2016 Accepted: 19 October 2016

Published online: 02 November 2016

\section{References}

1. Taheriazam A, Bahador R, Karbasy SH, Jamshidi SM, Torkaman A, Yahaghi E, Shakeri M. Down-regulation of microRNA-26a and up-regulation of microRNA-27a contributes to aggressive progression of human osteosarcoma. Diagn Pathol. 2015;10:166.

2. Song QC, Shi ZB, Zhang YT, Ji LL, Wang KZ, Duan DP, Dang XQ. Downregulation of microRNA-26a is associated with metastatic potential and the poor prognosis of osteosarcoma patients. Oncology Reports. 2014;31:1263-70
* Correspondence: mshakeri7@yahoo.com

${ }^{2}$ Department of Orthopaedic and Trauma Surgery, Birjand University of Medical Sciences, Birjand, Iran (c) The Author(s). 2016 Open Access This article is distributed under the terms of the Creative Commons Attribution 4.0 International License (http://creativecommons.org/licenses/by/4.0/), which permits unrestricted use, distribution, and reproduction in any medium, provided you give appropriate credit to the original author(s) and the source, provide a link to the Creative Commons license, and indicate if changes were made. The Creative Commons Public Domain Dedication waiver (http://creativecommons.org/publicdomain/zero/1.0/) applies to the data made available in this article, unless otherwise stated. 